\title{
Smartphones and Tablets as Endoscopic Surgical Trainers
}

\section{José Luis Mosso Vázquez ${ }^{1,2 *}$, David Gallardo Ceja ${ }^{2,3}$, Ivan Alvarez Martínez ${ }^{2}$, Jesus Antonio Gaytan², Viviana Dolores ${ }^{2}$, Luis Zararía Ramón ${ }^{2}$, Edmundo García Valle ${ }^{1}$, Sara del Carmen Santos Dimas ${ }^{1}$, Luis Ignacio Magaña Olguin ${ }^{1}$, Gregorio Tomás Obrador Vera ${ }^{1}$ and José Luis Mosso Lara ${ }^{4}$}

${ }^{1}$ School of Medicine, Universidad Panamericana, México City, Mexico

${ }^{2}$ Hospital General y Regional No. 25 of the IMSS, Mexico City, Mexico

${ }^{3}$ Unidad Médica de Alta Especialidad, Hospital de traumatología, Ortopedia y

Rehabilitación Dr. Victorio de la Fuente Narvaez, IMSS, Mexico City, Mexico

${ }^{4}$ Schjool of Medicine, Universidad Anahuac, Mexico

*Corresponding Author: José Luis Mosso Vázquez, School of Medicine, Universidad Panamericana, México City, Mexico.
Received: March 11, 2021

Published: April 23, 2021

(C) All rights are reserved by José Luis Mosso Vázquez., et al.

\begin{abstract}
Objective: We present hold graspers for tablets and smartphones as surgical trainers and the experience of this system training in one session with 5 residents of surgery.

Methodology: We designed an acrylic base of $25 \mathrm{~cm}$ length, $12 \mathrm{~cm}$ width and $2 \mathrm{~cm}$ of thickness. We install on this base a commercial tablet and smartphone holder (Specific for windshields). To the center and in the back of the holder we attached a horizontal arm, $22 \mathrm{~cm}$ large and $1.5 \mathrm{~cm}$ width, 2 holes end with $1 \mathrm{~cm}$ each in diameter (Holder for smartphones) and $30 \mathrm{~cm}$ lengths for tablets, getting the total systems $30 \mathrm{~cm}$ height and $25 \mathrm{~cm}$ width (See figure 1 and 2). 5 residents of surgery in the first year of residency at the Regional Hospital number 25 of the IMSS participated in 2010 (See figure 3). They trained just one session. They perform the following tasks, to grasp 4 acrylic cubes and 2 acrylic tubes with right grasper and place it to the left grasper and then place into a hole, the second task is performed knots.

Results: Remarkable decreasing time in both tasks are shown in graph 1 and 2 . Resident 2 and 3 performed 11 tasks more with remarkable results showing in graph 3 and 4 in a second session. In the beginning, training represents a degree of difficulty but later, warming up decreases time.

Conclusion: Surgical simulators need tablets and smart phones as endoscopes. The systems are easy to use and install. New generations as undergraduate students, residents, fellowships and surgeons are potential users. Up to this day, mobile's technology has developed in the last generation high resolution and new applications. Camera integrated permits us to become mobiles in zerodegree scope. With this experience residents used this trainer by 4 months all weekend after guards. We will design new trainers for new students' generations in future works and we started the program of laparoscopy in the school of medicine at the Universidad Panamericana in 2010 with this experience. This simulator is useful for warming up for laparoscopic surgeons before real endoscopic surgeries on humans also.
\end{abstract}

Keywords: Smartphone; Tablet; Surgical Trainer; Simulation

Citation: José Luis Mosso Vázquez., et al. "Smartphones and Tablets as Endoscopic Surgical Trainers". Acta Scientific Gastrointestinal Disorders 4.5 (2021): 43-47. 


\section{Introduction}

Tablets in operating rooms. 1. There are iPad apps in surgery as assisted tools in the Intraoperative, where surgeons manipulate the screen with his fingers covered with gloves. Tablets are covered by a sterilized and transparent acrylic, permitting them review medical imaging as $\mathrm{X}$ rays, sonographs, scanners, MRI, or virtual anatomy for orientation or planning surgical dissections [1]. 2. In the preoperative, smartphones are being using to demonstrate the utility for telemedicine, for instance, in our General and Regional hospital No. 25 of the IMSS, we send medical images form emergency department to anesthesiologist at the operating rooms, patient's pictures to evaluate aware, neck size, abdomen, arms, and the back for anesthesiologists and prepare operating room, medication, tracheal tube. Scrub nurse prepares surgical tools [2]. 3. iPhones for anesthesiologists is another application who Jason S. Lane et al use this system in Vanderbilt University Medical center, Nashville, TN, USA. They are demonstrating the utility in operating rooms, having a control of 4 operating rooms simultaneously before, during and after surgeries with an integrated mobile situational awareness smartphone application VigiVU ${ }^{\mathrm{TM}}$ at an academic medical center. With these apps, anesthesiologists can control their patients, in the preoperative, intraoperative and in the recovery, being safer and more productive. 4. In our hospital, we are using virtual scenarios, anatomical models Apps to distract patients while the surgeon performs ambulatory surgery (Cybertherapy), moving controls with the fingers, the patient can reduce his anxiety in the intra operative [3,4-6]. 5. Tablets in plastic surgery for planning surgery. There are iPad apps to manipulate cosmetic results in patients' faces on touch screens, changing nose, eyes, etc. 6 . Recently, surgeons use mobiles for telemedicine applications also in tablets for Surgical education. Surgical education progress needs books, journals, cadaver, animal models, physical trainers and increasingly virtual simulators before to participate in live surgeries like observer, assistant, and surgeon assisted by an expert, and finally surgeon alone. Once you are surgeon, open surgery is followed by endoscopic and robotic surgery. In the evolution of surgeons, the role of virtual simulator is essential. Virtual world permits education to progress in time, dexterity and visual motor development. Up to date, tablets and smartphones are in the classrooms of school of medicine for education proposals, for undergraduate students, mobiles are basic tools for elemental education [7-14].

\section{Materials and Methods}

Material: We designed a base in acrylic, $25 \mathrm{~cm}$ length, $12 \mathrm{~cm}$ width and $2 \mathrm{~cm}$ of thickness to support holders and mobiles. We place on this base a tablet or smartphone holder (Specific for windshields). In the back of the windshields holder, we attached a horizontal arm of $22 \mathrm{~cm}$ large and $1.5 \mathrm{~cm}$ width with 2 holes to each end with $1 \mathrm{~cm}$ diameter (Holder for smartphones) and another holder of $30 \mathrm{~cm}$ length for tablet, getting the total systems $25 \mathrm{~cm}$ height for mobiles and $30 \mathrm{~cm}$ width (See figure 1 and 2).

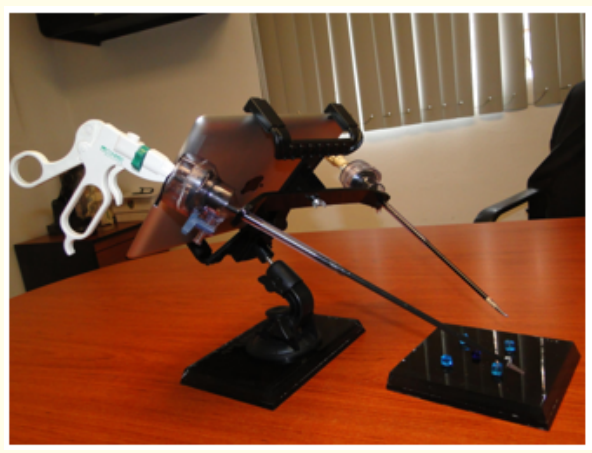

Figure 1: Tablet as surgical simulator.

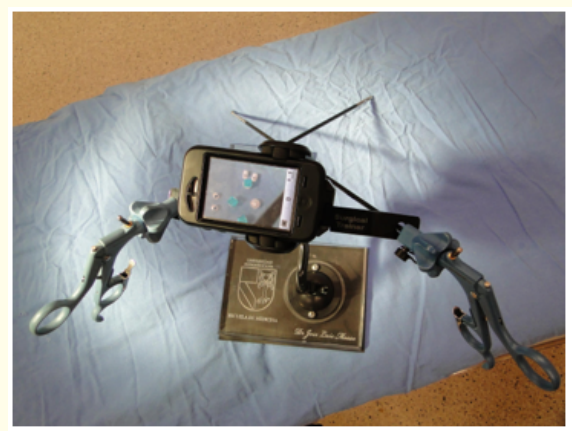

Figure 2: Smartphone as laparoscopic simulator.

\section{Methods}

5 residents of the first year of residency of surgery, 4 males and 1 female, with 22 mean age, participated at the General Hospital Number 25 of the IMSS (Instituto Mexicano del Seguro Social) in Mexico City in 2010. 6 months after starting residency, they participated in this study just in one session except two residents who decided to use in a second session. They trained one Saturday morning after a night guard with sleepless, we explained to them 10 minutes previously about the method of how to make knots and move acrylic cubes and tubes on the simulator. Two laparoscopic tasks they performed: first consist in to grasp with the right hand 
a grasper 4 acrylic cubes and 2 acrylic tubes and to place in the left grasper, and then to put them inside small holes in the surface of a flat acrylic square. Second task consists of performing knots (we measure seconds in each knot). Suture used was silk 0 with 12-centimeters length, a needle holder and a Maryland grasper. They used a smartphone (iPhones G4). An assistant measured time with a chronometer with additional mobile and helped to replace the base or items correctly and to cute silk sutures. Residents set up the system manually easily, positioning correctly the transverse arm behind the iPhone, they introduced real laparoscopic tools through holders to make the two tasks. In the case to move a small item ( 2 transparent acrylic tube measures of $5 \mathrm{~mm}$ length and 3 $\mathrm{mm}$ diameter and 4 blue acrylic cubes of $4 \mathrm{~mm}$ ) they take them with laparoscopic graspers. To perform knots, they used a laparoscopic needle holder and a grasper. We recorded seconds in knots each as total placement of cubes and tubes as well. Residents manipulated screens touching or pinching and getting zoom with their fingers. Data was integrated in Excel format to statistical analysis.

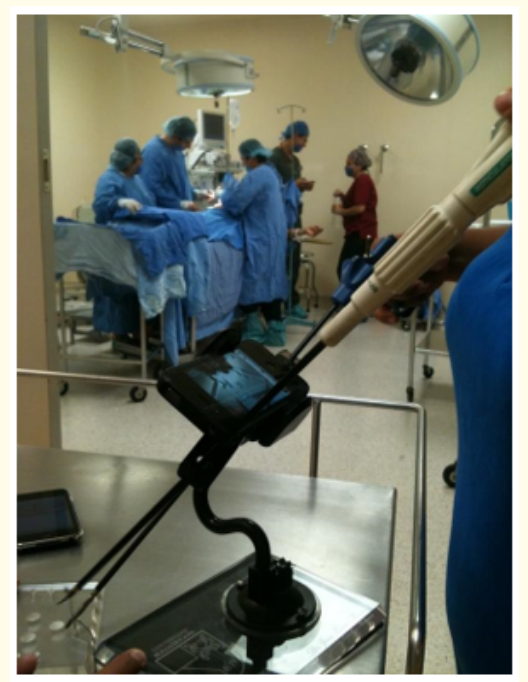

Figure 3: Residents performing surgical knots using smartphones as scope. Operating room. Hospital General y Regional No. 25,

IMSS Mexico City.

\section{Results and Discussion}

Remarkable time reduction placing acrylic cubes and tubes into holes as knots (See graph 1 and 2). Residents made both tasks with high degree of difficulty in the first attempt and a few minutes later of each assignment were enough to be friendly with the system and they made tasks in a short time at the sixth attempt. Residents start this training 4 months later starting the first year of residency in general surgery, during this first 4 months, they were first assistant of 24 laparoscopic surgeons in cholecystectomies, hiatal hernia repairs only. Any of them made a laparoscopic knot or manipulated laparoscopic graspers before this project (they manipulate just zero- and 30-degrees scopes). Residents presented pain in their fingers 30 minutes after training (Thumb and index fingers meanly). They present complete satisfaction during training. The main advantage in this training was the delay in the video transmission that limited the hand's speed of surgical training to move (in Real time) the needle holder, and graspers. All training was recorded with video apps by themselves. Light apps were necessary to visualize the surgical field. Pictures could be made when residents need them. System was resistant to harsh resident's movement. The system for tablet was developed, but the holders present instability giving users the risk of broken tablets.

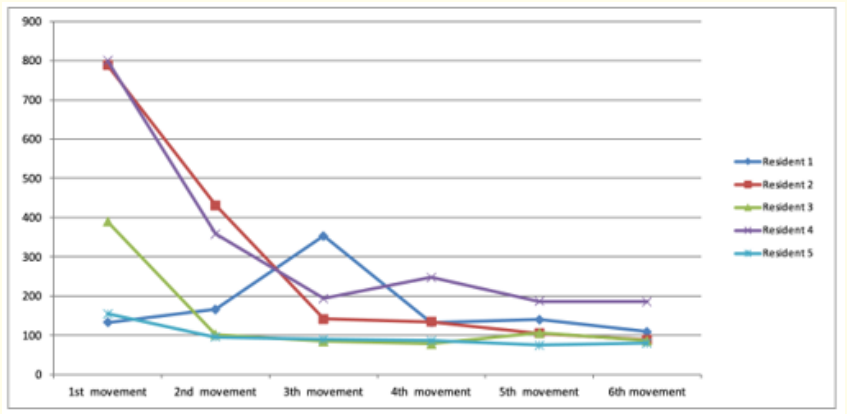

Graph 1: 5 Residents decreasing time per movement within each attempt training in the simulator (first time).

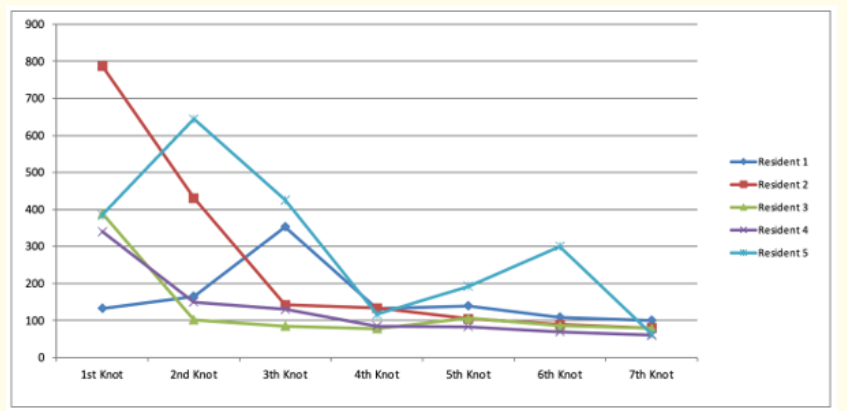

Graph 2: This graphic shows an impressive progress from the residents in making knots, reaching lesser time than in their firsts attempts (first time). 


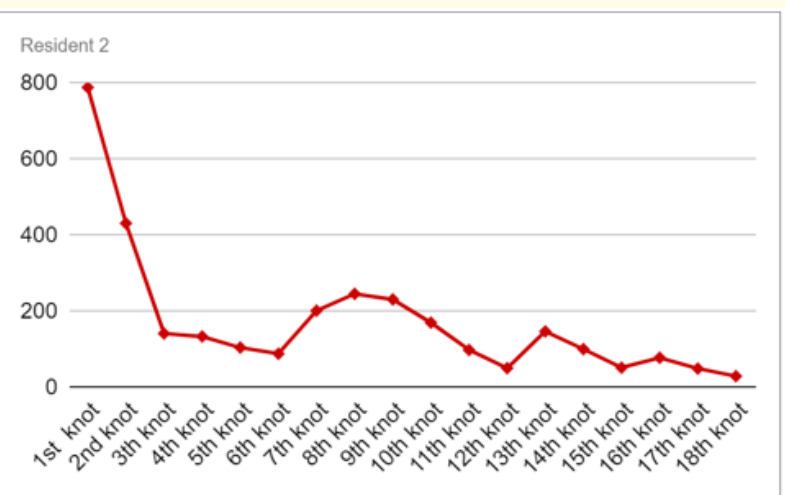

Graph 3: Resident (number 2) progress in eighteen knots attempts. From the first knot to the seventh were made on the first weekend, while the eighth to the eighteenth on the second (First and second weekend).

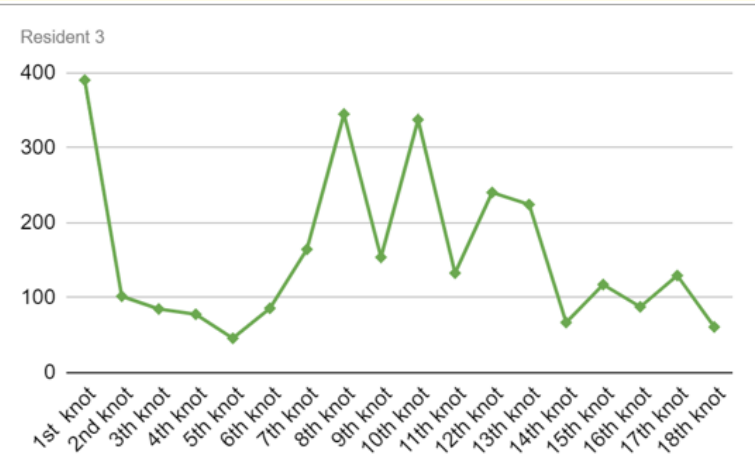

Graph 4: Resident (number 3) progress in eighteen knot attempts. The first seven tries were done on the first weekend, and the remaining knots on the second (first and second weekend).

\section{Preliminary Conclusions}

Smartphones and tablets are useful tools for daily life that can be used as surgical trainers. Must of undergraduate students, residents and surgeons are potentially users in Medicine. New generations are more involved in new technologies as smart phones and tablets. Smart phones and tablets avoid high investments in laparoscopic simulators that are expensive. We try to demonstrate that they are easy to become in lighter surgical trainers, that represent a daily tool in Medicine for undergraduate students. We suggest the following recommendations for users before using this surgical trainer: Setting vibrate phone mode, extended off-screen, battery charged, phone with zoom, phone with lamp, phone charger, optional second smartphone to record task's time. These two surgical trainers have been accepted in the program of Surgery matter in the second year of the career since 2010 at the school of Medicine in the Panamericana University. With this system we don't need big investments in surgical trainers, big space in operating rooms, and thus this simulator is easy to reproduce and 100 $\%$ of undergraduate students use a smartphone or tablets for academic applications. Smartphones and tablets can be used in these two lightweight bases and are attractive for students, funny, easy to use, easy to install with high resolution camera for photo and video apps and light integrated, necessary conditions to become surgical trainers.

\section{Acknowledgments}

Special thanks for the Regional and General Hospital number 25 administration from Instituto Mexicano del Seguro Social in México City (building in reconstruction by the earthquake on September 7 and 19 2017) for the opportunity to use this surgical trainer into operating rooms for residents of surgery. Special thanks to the 5 residents who gave their special resting time instead of going to rest home after sleepless in hard guards in this regional Hospital. They participated tired in the research but with so much enthusiasm interested and enjoying this fun experience as never seen before during 4 months on weekends after this session.

\section{Bibliography}

1. Benan M Dala-Ali., et al. "The uses of the iPhones for Surgeons". The Surgeon 9 (2011): 44-48.

2. Grossman L. "Invention of the year: the iPhone". The Times (2008).

3. Mosso Vázquez José Luis. "Smartphones in 2011 for Telemedicine in Emergency Surgery and 7 years later". Acta Scientific of Gastrointestinal Disorders Journal (2021): 1-6.

4. José Luis Mosso Vazquez., et al. "Pain Reduction with VR in Indigenous vs Urban Patients in Ambulatory Surgery". Annual Review of Cybertheory and Telemedicine 17 (2019): 99-104.

5. José Luis Mosso Vázquez., et al. “Virtual Reality Pain Mitigation During Elective Cesarean Surgical Delivery". Annual Review of Cybertherapy and Telemedicine 17 (2019): 105-112.

6. José Luis Mosso Vázquez., et al. "Virtual Reality and Minimal Analgesia Attenuate Pain During Spine Surgery". Annual Review of Cybertherapy and Telemedicine 17 (2019): 153-157. 
7. Roy M., et al. "Smartphone Application as an Education Platform in Hepato-Pancreato-Biliary Surgery". Surgical Innovation 26.5 (2019): 613-620.

8. Kulendran M., et al. "Surgical smartphone applications across different platforms: their evolution, uses, and users". Surgical Innovation 21.4 (2014).

9. Aebersold M. "The History of Simulation and Its Impact on the Future”. AACN Advanced Critical Care 27.1 (2016): 56-61.

10. Kleinert R., et al. "Embedding a Virtual Patient Simulator in an Interactive Surgical lecture". The Journal of Surgical Education 73.3 (2016): 433-441.

11. Childs BS., et al. "Novel Education and Simulation Tools in Urologic Training". Current Urology Reports 20.12 (2019): 81.

12. Pafitanis G., et al. "The use of mobile computing devices in microsurgery”. Archives of Plastic Surgery 46.2 (2019): 102-107.

13. Nehme J., et al. "Development and Evaluation of a Novel PanSpecialty Virtual Reality Surgical Simulator for Smartphones". Studies in Health Technology and Informatics 220 (2016): 251255.

14. Hoopes S., et al. "Home Surgical Skill Training Resources for Obstetrics and Gynecology Trainees During a Pandemic". Obstetrics and Gynecology 136.1 (2020): 56.

\section{Assets from publication with us}

- Prompt Acknowledgement after receiving the article

- Thorough Double blinded peer review

- Rapid Publication

- Issue of Publication Certificate

- High visibility of your Published work

Website: www.actascientific.com/

Submit Article: www.actascientific.com/submission.php

Email us: editor@actascientific.com

Contact us: +919182824667 